\title{
Ethanol Extract of Leaves of Cassia siamea Lam Protects against Diabetes-Induced Insulin Resistance, Hepatic, and Endothelial Dysfunctions in ob/ob Mice
}

\author{
Camille Koffi, ${ }^{1,2}$ Raffaella Soleti $\mathbb{D}^{2},{ }^{2}$ Mathieu Nitiema, ${ }^{2}$ Patricia Mallegol, ${ }^{2}$ Gregory Hilairet, ${ }^{2}$ \\ Julien Chaigneau, ${ }^{3}$ Jerome Boursier, ${ }^{3}$ Mamadou Kamagate, ${ }^{4}$ Soazig Le Lay, ${ }^{2}$ \\ Henri Maxime Die-Kakou, ${ }^{1}$ and Ramaroson Andriantsitohaina $\mathbb{( D}^{2}$ \\ ${ }^{1}$ Laboratory of Clinical Pharmacology, Université Félix Houphouët-Boigny, Côte d'Ivoire \\ ${ }^{2}$ INSERM UMR1063, Stress Oxydant et Pathologies Métaboliques, Faculté de Santé, Université d'Angers, Université Bretagne Loire, \\ Angers, France \\ ${ }^{3}$ EA 3859, Hémodynamique, Interaction Fibrose et Invasivité Tumorales Hépatiques (HIFIH), 49933 Angers, France \\ ${ }^{4}$ Laboratory of Clinical Pharmacology, University of Alassane Ouattara, Côte d'Ivoire
}

Correspondence should be addressed to Ramaroson Andriantsitohaina; ramaroson.andriantsitohaina@univ-angers.fr

Received 10 April 2019; Accepted 13 August 2019; Published 17 September 2019

Academic Editor: Shane Thomas

Copyright (c) 2019 Camille Koffi et al. This is an open access article distributed under the Creative Commons Attribution License, which permits unrestricted use, distribution, and reproduction in any medium, provided the original work is properly cited.

\begin{abstract}
Despite long traditional utilization and some reports on the antihyperglycemic and antihyperlipidemic action of Cassia siamea, the mechanisms involved have not been investigated yet. Thus, the objective of the present study was to investigate whether and how oral administration of the ethanolic extract of Cassia siamea Lam leaves (LECS) improves glucose and insulin homoeostasis, liver damage, and endothelial dysfunction in an experimental model of type 2 diabetes, the leptin-deficient $o b / o b$ mice. Oxidative stress and protein expression of insulin-dependent and insulin -independent signaling pathways were studied. Obese $(o b / o b)$ vs. control $(\mathrm{ob} /+)$ mice were treated daily with intragastric administration of either vehicle or LECS (200 mg/kg, per day) for 4 weeks. Fasting blood glucose, body weight, food intake, glucose and insulin tolerance, oxidative stress, and liver damage as well as vascular complications with respect to endothelial dysfunction were examined. Administration of LECS in obese mice significantly reduced blood glucose and insulin levels, improved glucose tolerance and insulin sensitivity, and restored the increase of circulating AST and ALT without modification of body weight and food intake. These effects were associated with increased activity of both insulin and AMPK pathways in the liver and skeletal muscles. Of particular interest, administration of LECS in obese mice completely prevented the endothelial dysfunction resulting from an increased $\mathrm{NO}^{\circ}$ and decreased reactive oxygen species (ROS) production in the aorta. Altogether, oral administration of LECS remarkably attenuates features of type 2 diabetes on glucose, hepatic inflammation, insulin resistance, endothelial function, and vascular oxidative stress, being as most of these effects are related to insulin-dependent and insulin-independent mechanisms. Therefore, this study points for the therapeutic potential of Cassia siamea in correcting both metabolic and vascular alterations linked to type 2 diabetes.
\end{abstract}

\section{Introduction}

Type 2 diabetes is highly prevalent and is one of the leading causes of mortality and morbidity worldwide, most often associated with obesity. Indeed, it affects over 400 million adults, and the number is expected to rise to 550 million by the year 2030 [1]. Type 2 diabetes is a multifactorial disease involving genetic and environmental factors [2]. The pathophysiological changes are characterized by $\beta$-cell dysfunction, insulin resistance in the liver, and skeletal muscle and chronic inflammation, all of which hamper control of blood glucose levels and contribute to the development of vascular complications. Traditional antihyperglycemic drugs have helped to improve glycemic control without reducing cardiovascular complications. Pharmacological and life style interventions should address all potential risk factors to 
improve the cardiovascular outcomes in patients with type 2 diabetes [3].

It is generally accepted that medicinal plants can have health-promoting properties [4] and can be therapeutic alternatives in the management of type 2 diabetes [5]. This strategy involves exploitation of the potential medicinal plants from the local pharmacopoeia. In this context, several studies have shown that plant extracts are veritable sources of antidiabetic compounds [6]. For example, Madeglucyl and metformin, both oral antidiabetic drugs, are isolated from Eugenia jambolana (Rutaceae) and Galega officinalis (Fabaceae), respectively $[7,8]$. The mechanisms of natural products for glucose control in diabetes include the inhibition of glucose absorption (via inhibition of the glucose transporter (GLUT)), improvement of insulin sensitivity, protection of $\beta$-cell damage, increase of insulin release, enhancement of antioxidant defense, attenuation of inflammation, and modulation of carbohydrate metabolism pathway. These effects are under the regulation of insulin-dependent (via insulin receptor, $\mathrm{IR}_{\beta}$, and $\mathrm{Akt}$ ) and insulin-independent (via adenosine monophosphate-activated protein kinase (AMPK)) signaling pathways $[9,10]$.

Cassia siamea Lam (Fabaceae), a folklore medicinal plant, is known for its therapeutic potential in diabetes and hypertension [11]. Phytochemical screening of this plant reveals the presence of polyphenols, flavonoids, isoflavonoids, phenolic acids, triterpenoids, chromones, anthraquinones, bianthraquinones, sennosides, steroids, and carotenoids [10]. Previous pharmacological studies show that organic and aqueous extracts of Cassia siamea possess high antioxidant potential [12], reduce hyperglycemia by $39.38-54.32 \%$, improve lipid profile in alloxan-induced diabetes rats $[13,14]$, and induce vasodilatation in isolated rat mesenteric arteries [15]. Cassiamin A, isolated from the ethyl acetate extract of Cassia siamea, exhibits pancreatic lipase inhibitory activity that participates in its antiobesity effect [16].

This study was undertaken to investigate the effects of the antidiabetic potential of the leaf ethanol extract of Cassia siamea Lam (LECS) that takes into account glucose control via insulin-dependent and insulin-independent pathways on the hepatic damage and inflammation and vascular defects, namely, endothelial dysfunction in an experimental model of type 2 diabetes, i.e., the leptin-deficient $o b / o b$ mice.

\section{Materials and Methods}

2.1. Plant Material. The fresh leaves of Cassia siamea (ITIS No. 505177) were collected in Adiopodoumé (Ivory Coast), in June 2015. This plant has been authenticated by Doctor Assi Yapo, a botanist in the Department of Biosciences at the Centre National de Floristique (Université Félix Houphouët-Boigny, Abidjan, Ivory Coast), and the voucher specimen was registered under No. 126/97.

2.2. Extraction Procedure. Ethanol extract was prepared as previously described [13]. Briefly, the fresh leaves of C. siamea were washed, dried, pulverized, and extracted by cold maceration in ethanol $(80 \%)$ for $48 \mathrm{~h}$. Then, the extract was filtered, distilled off at $40^{\circ} \mathrm{C}$ in a circulating air oven (Mem- mert ${ }^{\circledR}$, Germany) to obtain a powder LECS, and stored at $4^{\circ} \mathrm{C}$ until use. The extraction ratio expressed as LECS mass/powder of leaf mass was 0.14 .

2.3. Ethics Statement. Present study was conducted in accordance with the guidelines and authorization with French Ministry of Agriculture regulations based on the European Community. Upon local ethics committee approval, the animal protocol followed in the present study was authorized by the French Ministry of National Education, Higher Education and Research (APAFIS\#265-2015110916015679 v2).

2.4. Animals. Three- to four-month-old $o b / o b$ or $o b /+$ male and female mice were obtained from the animal housing unit of the University of Angers (Angers, France) and maintained under an environmentally controlled facility (temperature $22^{\circ} \mathrm{C}$ and 12-hour light and dark cycles) with free access to food and water. The animals were acclimatized for 7 days prior to the experiments and provided rodent chow and water ad libitum. The leptin genotypes of the animals were verified by the PCR method at the laboratory.

\subsection{Pharmacological Study}

2.5.1. Treatment. Four groups of animals have been constituted: two groups of obese mice ( $n=8$ mice for each group) and two groups of controls ( $n=8$ mice for each group). Obese mice and their wild type were treated daily for 28 days by intragastric gavage either with vehicle ( $2 \%$ Tween 80 ) or with LECS (200 mg/kg, per day). The dose $200 \mathrm{mg} / \mathrm{kg} /$ day of LECS was chosen as the most effective in exhibiting antihyperglycemic properties in an experimental model of a diabetic rat [13].

2.5.2. Food Intake, Body Weight, and Fasting Blood Glucose. Food intake and body weight gain of all mice were monitored during the 28-day experimental period. At an interval of 7 days, blood samples were collected from the tail vein of the mice after overnight fasting for the estimation of the blood glucose level using a glucometer (Freestyle Seed Optium ${ }^{\circledR}$, Australia) and compatible blood glucose test strips.

\subsubsection{Glucose Tolerance Test (GTT) and Insulin Tolerance} Test (ITT). After twenty-one days of treatment, mice were fasted overnight for GTT. Fasting glycemia was measured and defined as time zero $(0 \mathrm{~min})$. Then, all animal groups received an intraperitoneal (i.p.) load of (+) D-glucose $(1.0 \mathrm{~g} / \mathrm{kg})$. Tail vein blood samples were withdrawn 10,20 , $30,60,90$, and $120 \mathrm{~min}$ after the administration of glucose. Blood glucose was monitored using a glucometer.

ITT was performed on the twenty-fifth day of treatment. Tail blood was collected before ( $0 \mathrm{~min})$ and at $15,30,45$, and $60 \mathrm{~min}$ after i.p. injection of insulin $(0.75 \mathrm{U} / \mathrm{kg})$.

2.5.4. Sample Collection. At the end of the experimental protocol, mice were euthanized by gradient $\mathrm{CO}_{2}$ inhalation. The liver and soleus skeletal muscle were isolated, weighed, immediately placed in liquid nitrogen, and stored at $-80^{\circ} \mathrm{C}$ until further use, while the thoracic aorta was isolated for vascular reactivity assessment. 


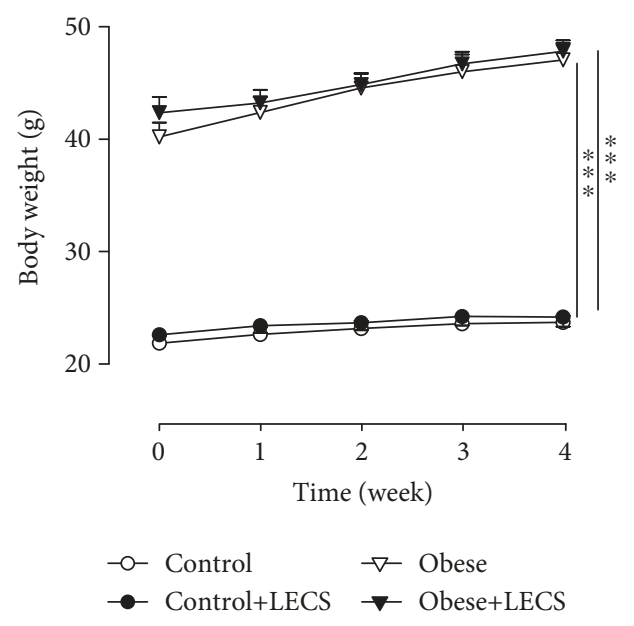

(a)

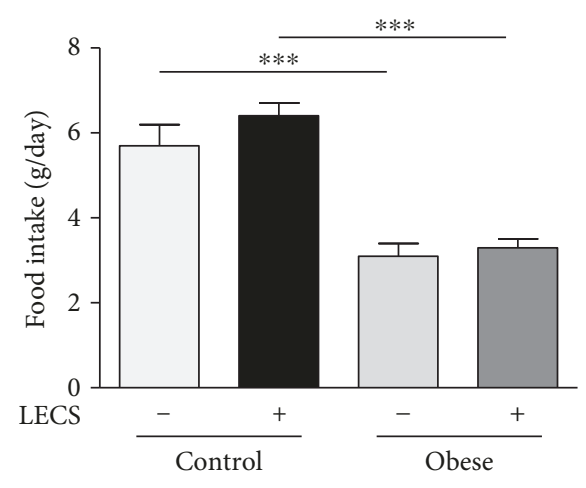

(b)

FIGURE 1: LECS does not affect body weight gain and food intake of $o b / o b$ mice. Effects of LECS on body weight (a) and food intake (b) after 4 -week administration in $o b / o b$ and control mice. The results are expressed as mean \pm S.E.M. ( $n=8 /$ group; ${ }^{* * *} p<0.001$ vs. lean mice).

2.5.5. Biochemical Analysis. Blood samples were centrifuged at $900 \mathrm{~g}$ for $10 \mathrm{~min}$ to obtain plasma, which was stored at $-20^{\circ} \mathrm{C}$ until the following parameters had been determined: glucose, aspartate aminotransferase (AST) and alanine aminotransferase (ALT), triglycerides, cholesterol, HDL, and LDL using a Konelab ${ }^{\mathrm{TM}} 20$ Clinical Chemistry Analyzer (Thermo Scientific ${ }^{\mathrm{TM}}$, Waltham, MA). Plasma insulin was determined by ELISA (Millipore, Germany).

2.5.6. Western Blotting. Tissue samples from the liver and muscle were frozen in liquid nitrogen and homogenized in a buffer containing $500 \mu \mathrm{L}$ sodium dodecyl sulfate (SDS, $20 \%$ ), $100 \mu \mathrm{L}$ sodium orthovanadate, $50 \mu \mathrm{L} \mathrm{Na}$ pyrophosphate, $200 \mu \mathrm{L}$ Tris $\mathrm{HCl} 500 \mathrm{mM}$ (pH 7.4), and $400 \mu \mathrm{L}$ antiprotease. The tissue suspensions are centrifuged at $15000 \mathrm{~g}$ for $15 \mathrm{~min}$ at $4^{\circ} \mathrm{C}$. Supernatants containing the proteins were collected and stored at $-80^{\circ} \mathrm{C}$ until use. Forty $\mu \mathrm{g}$ of proteins from tissue lysates were run on $10 \%$ reducing SDSacrylamide gels (Invitrogen, Carlsbad, CA). The samples were electrotransferred to nitrocellulose membranes, and the membranes were then saturated at room temperature

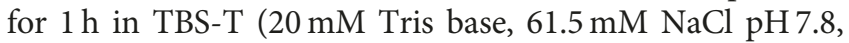
and $0.1 \%$ Tween 20 ) buffer containing $5 \%$ bovine serum albumin (BSA). After washing, the membranes were incubated with a primary antibody for $2 \mathrm{~h}$ and then incubated for $90 \mathrm{~min}$ either with horseradish peroxidase-secondary anti-rabbit or with anti-mouse antibodies (USBiological, Salem, MA). The blots were visualized using the enhanced chemiluminescence system (ECL Plus, Amersham Biosciences, Piscataway, NJ) and the SuperSignal West Femto (Thermo Scientific Pierce, Brebières, France) and quantified by densitometry. The primary antibodies used were polyclonal anti-phospho-Akt (Ser 473) (SAB, College Park, MD), polyclonal anti-Akt (Cell Signaling Technology, Danvers, MA), polyclonal anti-phospho-AMPK $\alpha$ (Thr172) (Cell Signaling Technology), polyclonal anti-AMPK $\alpha$ (Cell Signaling Technology), polyclonal anti-phospho-insulin receptor $\beta$ (Y1162/1163) (Santa Cruz Biotechnology, Santa Cruz, CA), polyclonal anti-insulin receptor $\beta$ (Santa Cruz Biotechnology), polyclonal anti-GLUT4 (Santa Cruz Biotechnology), polyclonal anti-GLUT2 (Santa Cruz Biotechnology), and polyclonal anti- $\beta$-actin (Sigma-Aldrich, St. Louis, MO).

2.5.7. Nitric Oxide (NO) and Reactive Oxygen Species (ROS) Evaluation. Detection of $\mathrm{NO}^{\circ}$ and ROS productions in mice femoral artery rings was performed using a previously described electronic paramagnetic resonance technique (Spectrometer MiniScope MS200, Magnettech, Berlin, Germany) [17]. $\mathrm{Fe}^{2+}$ diethyldithiocarbamate (DETC, Sigma-Aldrich) was used as a spin trap for NO; whereas ROS detection was performed using deferoxamine-chelated Krebs-HEPES solution containing 1-hydroxy-3-methoxycarbonyl-2,2,5,5-tetramethylpyrrolidine (CMH $500 \mu \mathrm{mol} / \mathrm{L}$, Noxygen, Mainz, Germany), deferoxamine ( $25 \mu \mathrm{mol} / \mathrm{L}$, Sigma-Aldrich), and DETC ( $5 \mu \mathrm{mol} / \mathrm{L}$, Sigma-Aldrich).

2.5.8. Ex Vivo Vascular Reactivity. After 28 days of treatment, the aorta from control and obese mice was dissected and placed in modified Krebs-Henseleit bicarbonate solution composed of $\mathrm{NaCl}(130 \mathrm{mM}), \mathrm{NaHCO}_{3}(14.9 \mathrm{mM}), \mathrm{KCl}$ (3.7 mM), $\mathrm{KH}_{2} \mathrm{PO}_{4}(1.2 \mathrm{mM}), \mathrm{MgSO}_{4}(1.2 \mathrm{mM}),(+) \mathrm{D}-$ glucose $(11 \mathrm{mM})$, and $\mathrm{CaCl}_{2}(1.6 \mathrm{mM})$. Then, aortic rings were mounted on a wire myograph (Danish Myo Technology, Aarhus, Denmark) as previously described [18] containing $7 \mathrm{~mL}$ oxygenated $\left(95 \% \mathrm{O}_{2}, 5 \% \mathrm{CO}_{2}\right)$ Krebs-Henseleit solution $\mathrm{pH} 7.4$ and maintained at $37^{\circ} \mathrm{C}$. The functionality of the endothelium was assessed by the ability of acetylcholine (Ach, Sigma-Aldrich) to induce relaxation. Thus, cumulative addition of Ach $\left(10^{-9}-10^{-5} \mathrm{M}\right)$ was assessed on a vessel precontracted with the thromboxane analogue (U46619 , Sigma-Aldrich) at $80 \%$ of its maximal contraction. Concentration-response curves produced by Ach in aortic rings were expressed as a percentage of the precontraction by U-46619.

In addition, in another set of experiments, the effect of LECS on vasorelaxation was assessed in aortic rings from 
TABLE 1: Effect of LECS on plasma lipid levels.

\begin{tabular}{lcccc}
\hline & Control & Control+LECS & Obese & Obese+LECS \\
\hline Triglycerides (g/L) & $0.57 \pm 0.04$ & $0.53 \pm 0.05$ & $0.53 \pm 0.06$ & $0.56 \pm 0.08$ \\
Cholesterol (g/L) & $1.1 \pm 0.1$ & $0.9 \pm 0.05$ & $1.3 \pm 0.1$ & $1.3 \pm 0.2$ \\
HDL (g/L) & $0.79 \pm 0.06$ & $0.86 \pm 0.07$ & $1.09 \pm 0.1$ & $1.07 \pm 0.13$ \\
LDL (g/L) & $0.13 \pm 0.01$ & $0.1 \pm 0.02$ & $0.15 \pm 0.02$ & $0.17 \pm 0.03$ \\
\hline
\end{tabular}

Triglycerides, cholesterol, HDL, and LDL plasma concentration in control and obese mice treated or not with LECS. The results are expressed as mean \pm SEM.

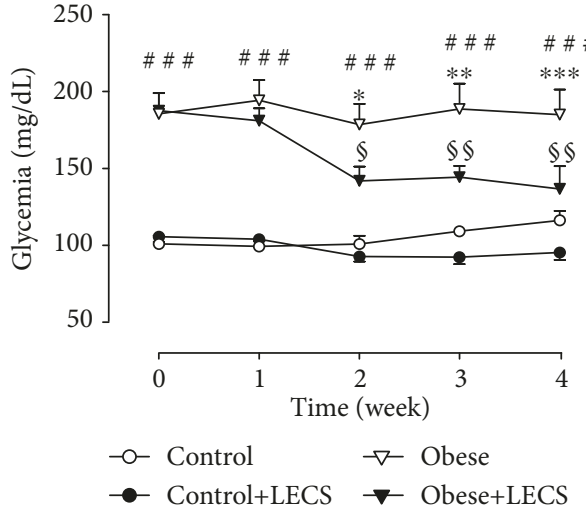

(a)

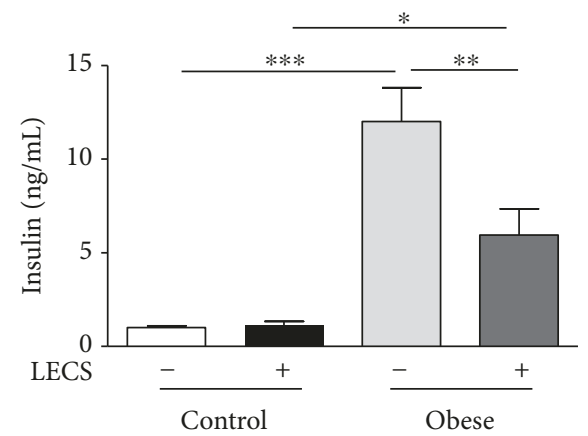

(c)

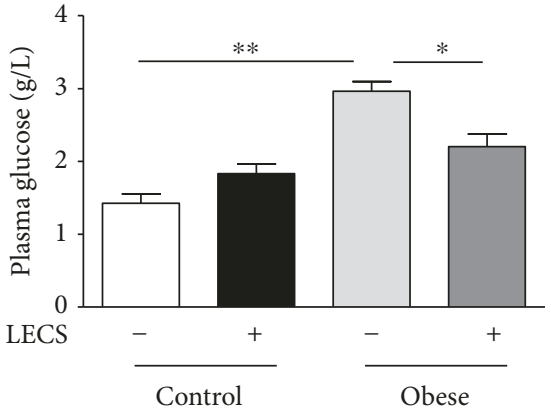

(b)

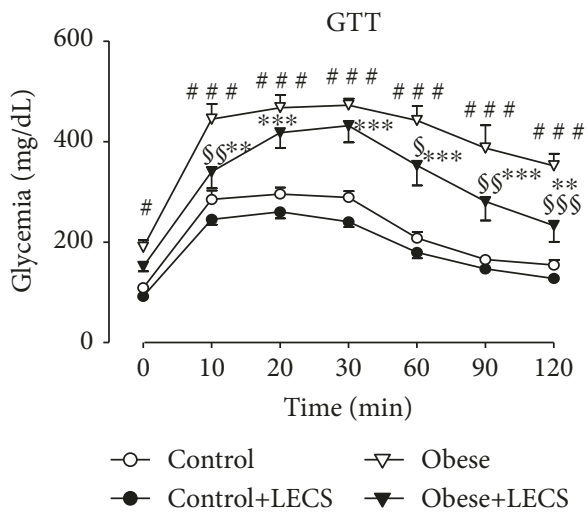

(d)

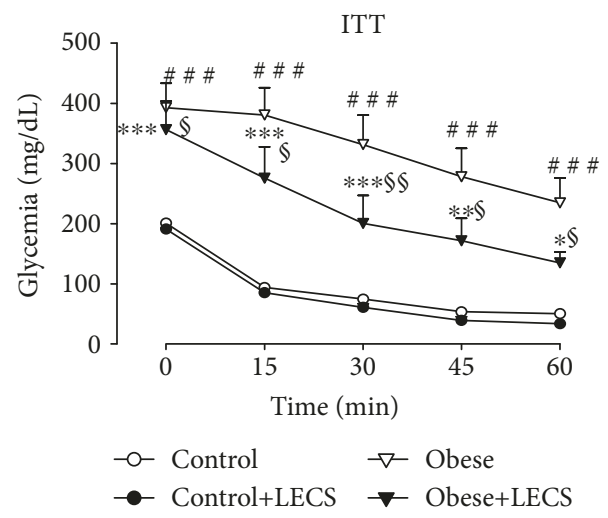

(e)

FIGURE 2: LECS exhibits antihyperglycemic effects and improves glucose and insulin tolerance of $o b / o b$ mice. Effects of LECS on fasting blood glucose (a), plasma glucose (b), insulin (c), glucose (d), and insulin (e) tolerance, after intraperitoneal (i.p.) administration either of D-glucose $(1.0 \mathrm{~g} / \mathrm{kg})$ or insulin $(0.75 \mathrm{UI} / \mathrm{kg})$. The results are expressed as mean \pm S.E.M. $\left(n=8 /\right.$ group; ${ }^{\#} p<0.05,{ }^{\# \#} p<0.01$, and ${ }^{\# \# \#} p<0.001$ vs. control; ${ }^{*} p<0.05,{ }^{* *} p<0.01$, and ${ }^{* * *} p<0.001$ vs. control+LECS; ${ }^{*} p<0.05,{ }^{* *} p<0.01$, and ${ }^{* * *} p<0.001$ vs. control+LECS; ${ }^{\circledR} p<0.05,{ }^{\$ \S} p<0.01$, and ${ }^{\$ S \$} p<0.001$ vs. obese). 


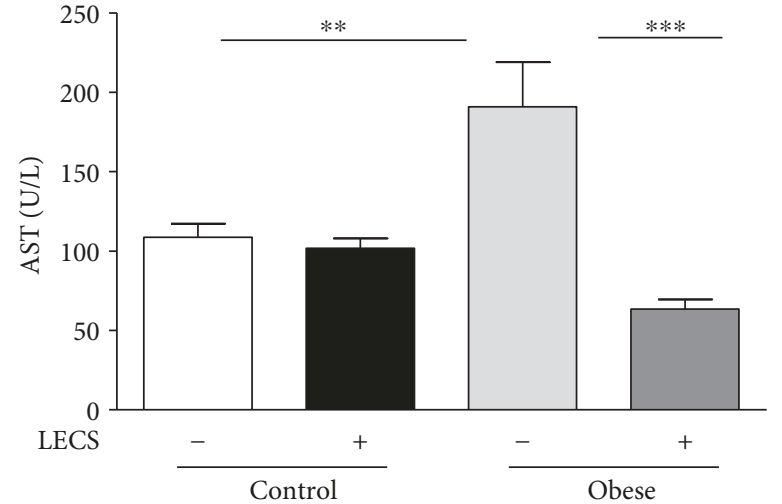

(a)

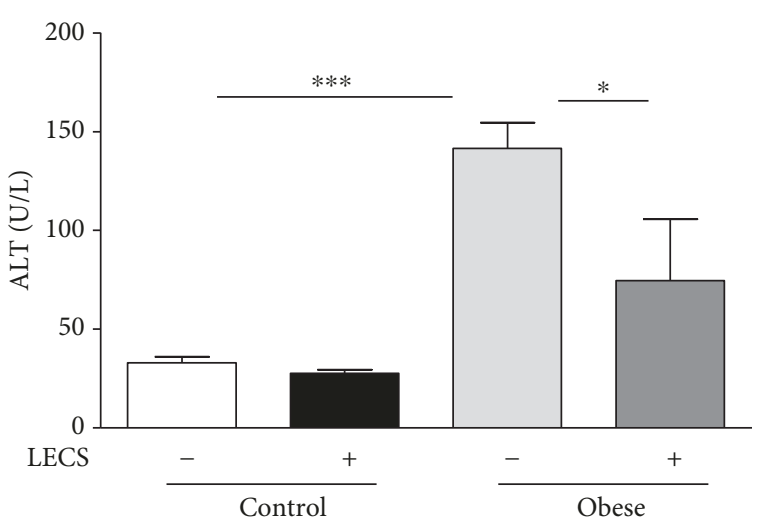

(b)

FIGURE 3: LECS improves hepatic parameters in diabetic ob/ob mice. Effects of LECS on hepatic function parameters in lean and $o b / o b$ mice: (a) aspartate aminotransferase (AST); (b) alanine aminotransferase (ALT). The results are expressed as mean \pm S.E.M. $\left(n=8 /\right.$ group; ${ }^{*} p<0.05$, ${ }^{* *} p<0.01$, and $\left.{ }^{* * *} p<0.001\right)$.

wild-type mice and the $\mathrm{EC}_{80}(500 \mu \mathrm{g} / \mathrm{mL})$ was calculated. Then, the implication of endothelium-derived relaxing factors, in response to LECS response such as $\mathrm{NO}^{\circ}$ and prostacyclin, were evaluated using specific NO-synthase

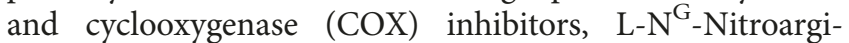
nine Methyl Ester (L-NAME, $10^{-4} \mathrm{M}$ ) and indomethacin $\left(10^{-5} \mathrm{M}\right)$, respectively.

After that, LECS pretreatment on insulin vasorelaxation action was evaluated. Indeed, aortic rings from wild-type mice were isolated and incubated with $500 \mu \mathrm{g} / \mathrm{mL}$ LECS for $30 \mathrm{~min}$ and then precontracted with U-46619 $\left(10^{-8} \mathrm{M}\right)$. When the contraction reached a steady state, increasing concentrations of insulin $\left(10^{-8}-3.10^{-5} \mathrm{M}\right)$ were added cumulatively to produce relaxation. The relaxation produced by insulin was expressed as a percentage of the U-46619induced contraction.

2.6. Statistical Analysis. Statistical analysis was performed using GraphPad Prism 5.1 ${ }^{\circledR}$ software. Data were expressed as mean \pm SEM of five to eight replicates and subjected to one-way or two-way analysis of variance (ANOVA) followed, when necessary, by Turkey's test or the Bonferroni posttest to determine significant differences in all the parameters. Values were considered statistically significant at $p<0.05$.

\section{Results}

3.1. LECS Does Not Affect Body Weight and Food Intake in Obese Mice. Figure 1 shows that ob/ob mice displayed a greater body weight and lower food intake compared to lean mice. LECS did not significantly modify the body weight and the food intake in the two groups of mice.

3.2. LECS Does Not Affect Plasma Lipid Levels. LECS treatment did not modify triglyceride, cholesterol, HDL, and LDL levels, independently from the strain (Table 1).

3.3. LECS Exhibits Antihyperglycemic Effects and Improves Glucose and Insulin Tolerance in Obese Mice. Obese mice displayed a greater circulating glucose level compared to control mice (Figure 2). LECS $(200 \mathrm{mg} / \mathrm{kg})$ treatment did not modify the glycemia of lean mice. Interestingly, LECS reduced significantly hyperglycemia in a time-dependent manner in $o b / o b$ mice $(p<0.01)$, the effect being maximal after the 2-week treatment (Figure 2(a)). Thus, at the end of treatment, LECS significantly reduced the level glucose of $o b / o b$ mice $(p<0.05)$ towards that of control mice (Figure 2(b)). Also, obese mice exhibited a greater circulating insulin level compared to control mice (Figure 2(c)). LECS treatment did not modify the insulin level in lean mice but reduced that of $o b / o b$ mice.

The GTT revealed that, after receiving the glucose overload, ob/ob mice developed higher values of glycemia than the control animal group throughout the assay $(p<0.001$, Figure 2(d)). Interestingly, LECS significantly decreased the glucose overload in $o b / o b$ mice but not in control animals. The ITT showed that, after receiving insulin injection, the decrease of blood glucose levels was significantly greater after LECS treatment in $o b / o b$ mice but not in control animals (Figure 1(e)). These results indicate that LECS improves glucose and insulin intolerance in diabetic ob/ob mice.

3.4. LECS Improves Hepatic Parameters in Obese Mice. The untreated $o b / o b$ mice exhibited significant increase $(p<0.05)$ in plasma activities of ALT and AST when compared with those of control mice (Figure 3). LECS treatment in $o b / o b$ mice restored the increases of ALT and AST toward those from control mice suggesting that the extract corrects liver dysfunction.

3.5. LECS Beneficial Effects in the Liver and Skeletal Muscle in Obese Mice. The activation/expression of proteins involved in intracellular glucose utilization pathways, such as $\mathrm{IR}_{\beta}$, Akt, AMPK, and GLUTs in the liver and skeletal muscle of $o b / o b$ versus control mice, was performed (Figures 4 and 5).

Semiquantitative analysis of $\mathrm{IR}_{\beta}$, Akt, AMPK, GLUT2, and GLUT4 showed that their expressions were not significantly altered either in tissues from ob/ob mice or in those treated by LECS when compared to that of control mice. Interestingly, the phosphorylation isoform of AKT and 


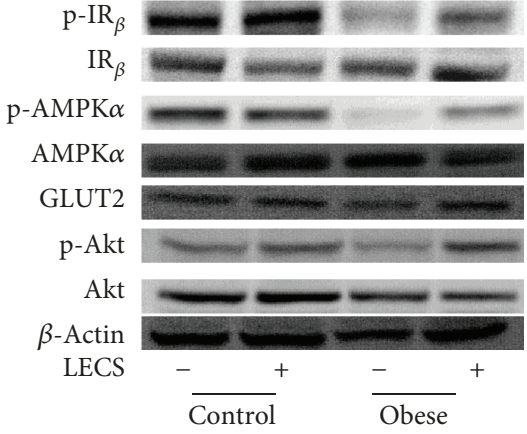

(a)

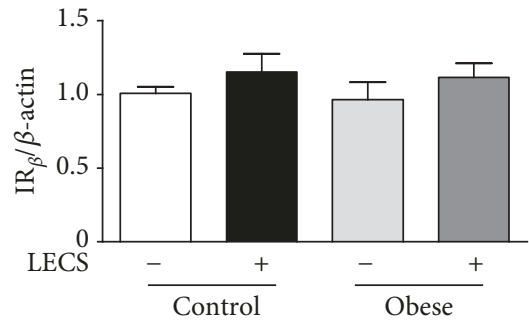

(c)

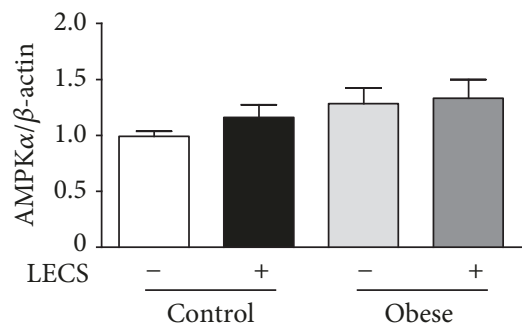

(e)

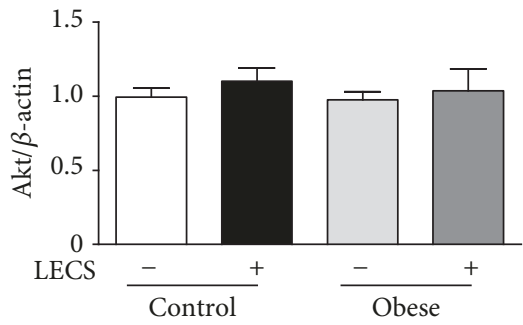

(g)

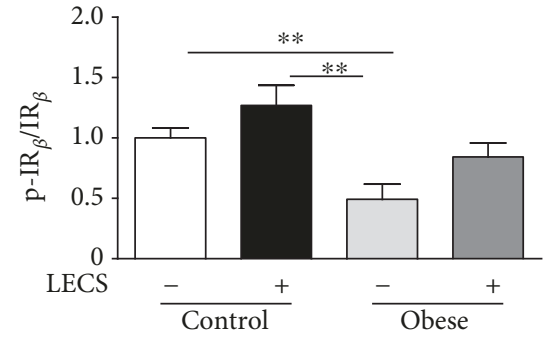

(b)

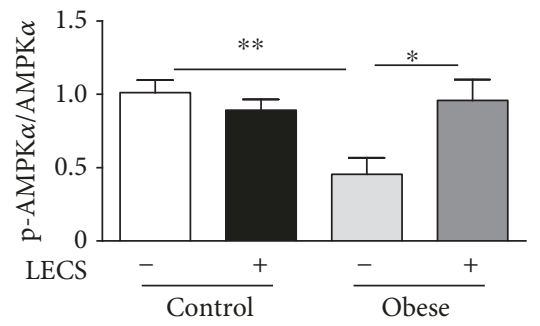

(d)

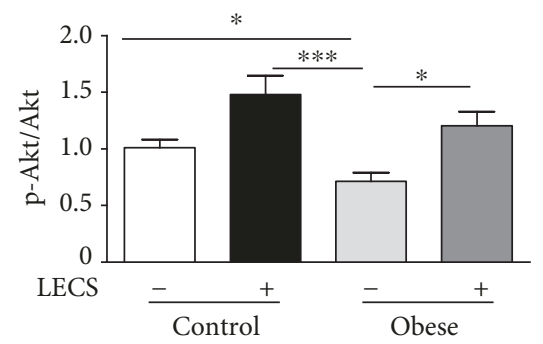

(f)

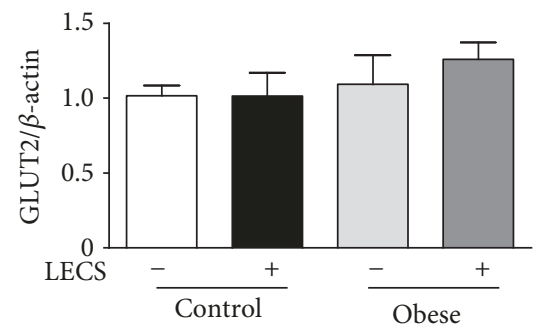

(h)

FIgURE 4: LECS upregulates Akt and AMPK $\alpha$ pathways in the liver of diabetic ob/ob mice. (a) Representative images of blots. Quantitative

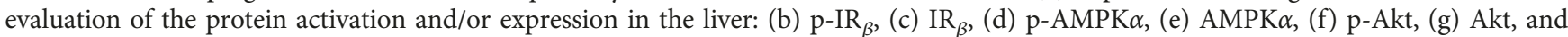
(h) GLUT2. The results are expressed as mean \pm S.E.M. $\left(n=8\right.$ /group; ${ }^{*} p<0.05,{ }^{* *} p<0.01$, and ${ }^{* * *} p<0.001$.

AMPK that was reduced in $o b / o b$ mice was significantly enhanced by LECS treatment. Taken together, these findings suggest that LECS improved both insulin and AMPK signaling in skeletal and liver tissues from $o b / o b$ mice.

3.6. LECS Prevents Endothelial Dysfunction. As expected, the endothelium-dependent relaxation in response to Ach was significantly impaired in the aorta taken from ob/ob mice compared to control mice (Figure 6(a)). Remarkably, LECS treatment significantly potentiated the endotheliumdependent relaxation to Ach in the aorta from $o b / o b$ mice (Figure 6(b)) but not from control mice (not shown). Thus,
Ach response of aortic $o b / o b$ mice treated with LECS was reverted toward that of the aorta from control mice. The impaired relaxation to Ach in $o b / o b$ mice was associated with a significant decrease of $\mathrm{NO}^{\circ}$ and increase of ROS productions in the femoral artery (Figures 6(c) and 6(d)). LECS had no effect on either NO or ROS in the femoral artery from control mice. Interestingly, LECS significantly inhibited the increase of ROS in the femoral artery from $o b / o b$ mice.

3.7. LECS Induces Endothelium-Dependent and EndotheliumIndependent Relaxation. LECS $(10-2000 \mu \mathrm{g} / \mathrm{mL})$ induced a 


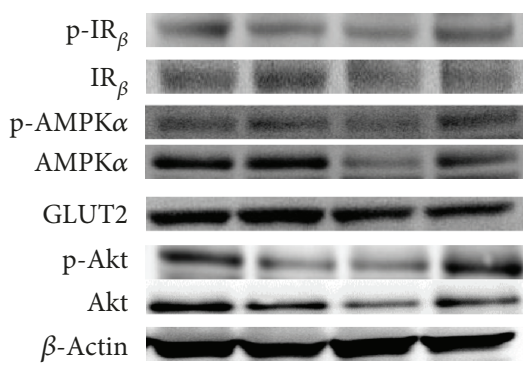

(a)

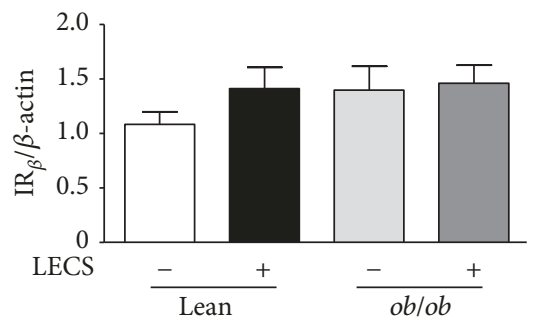

(c)

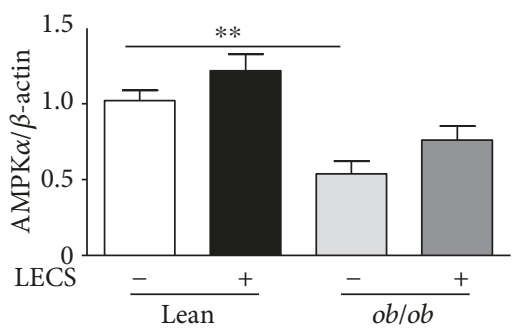

(e)

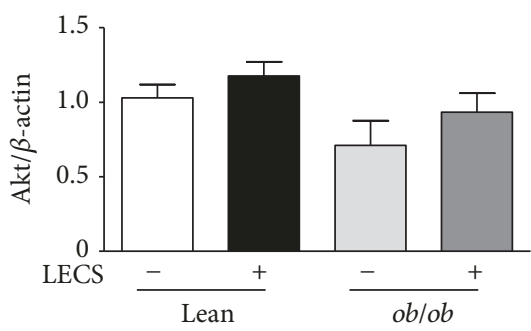

(g)

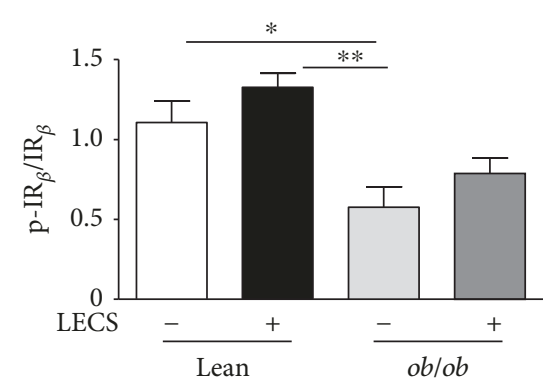

(b)

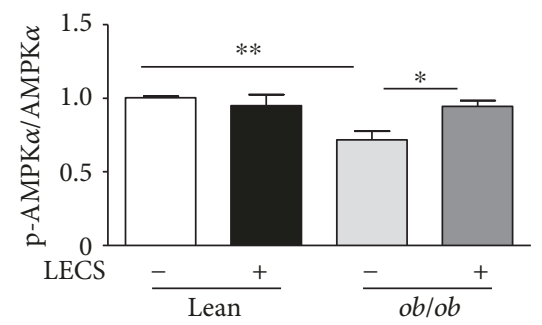

(d)

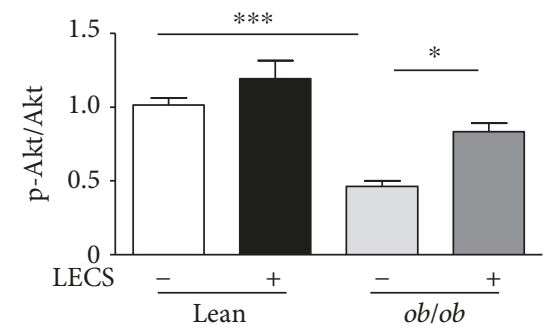

(f)

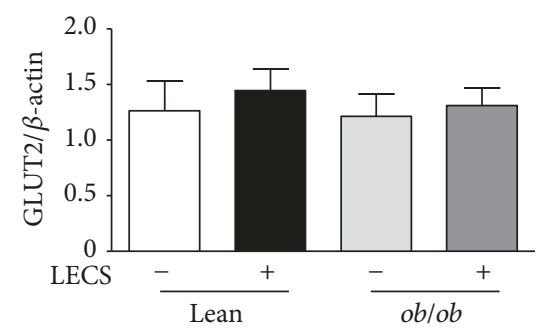

(h)

FIgURE 5: LECS upregulates Akt and AMPK $\alpha$ pathways in the skeletal muscle of diabetic ob/ob mice. (a) Representative images of blots. Quantitative evaluation of the protein activation and/or expression in the skeletal muscle: (b) p-IR ${ }_{\beta}$, (c) $\operatorname{IR}_{\beta}$, (d) p-AMPK $\alpha$, (e) AMPK $\alpha$, (f) p-Akt, (g) Akt, and (h) GLUT4. The results are expressed as mean \pm S.E.M. $\left(n=8 /\right.$ group; ${ }^{*} p<0.05,{ }^{* *} p<0.01$, and $\left.{ }^{* * *} p<0.001\right)$.

concentration-dependent relaxation of aortic rings either in the presence or in the absence of a functional endothelium (Figure 7). However, LECS was more efficient in the presence of an endothelium compared to an endothelium-denuded aorta as shown by a significant rightward shift of the concentration-response curve to the compound in the endothelium-denuded aorta (Figure 7(a)). Also, LECS relaxation curves were significantly shifted to the right in the presence of either the NO-synthase inhibitor, L-NAME, or the COX-inhibitor, indomethacin (Figures 7(b) and 7(c)). Besides, preincubation of the aortic rings with LECS
(500 $\mu \mathrm{g} / \mathrm{mL})$ significantly potentiated the endotheliumdependent relaxation to insulin (Additional file $2 \mathrm{~d}$ ).

\section{Discussion}

The present study provides evidence that in an experimental model of severe obesity, LECS reduced blood glucose and insulin levels, improved glucose tolerance and insulin sensitivity, and increased activity of hepatic transaminases without modification of body weight and food intake. Accordingly, the improvement of the insulin sensitivity 


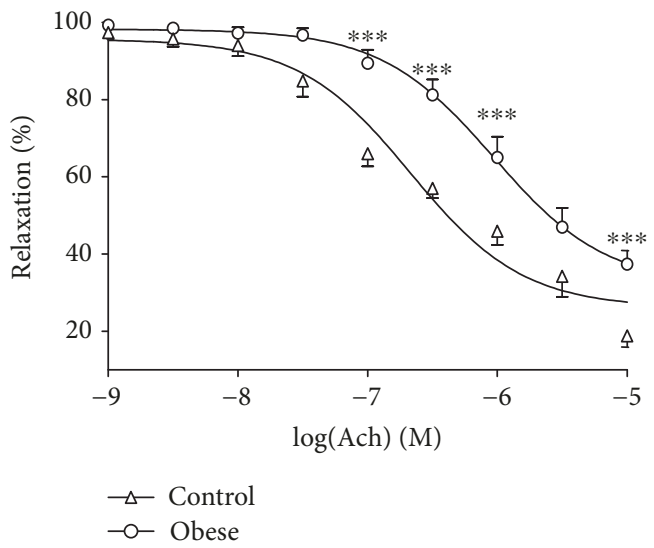

(a)

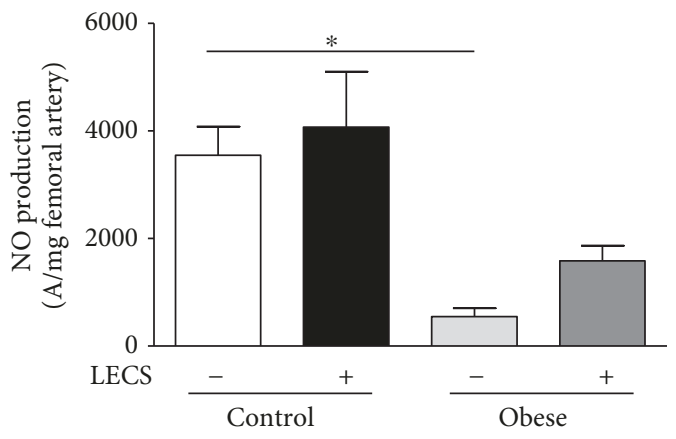

(c)

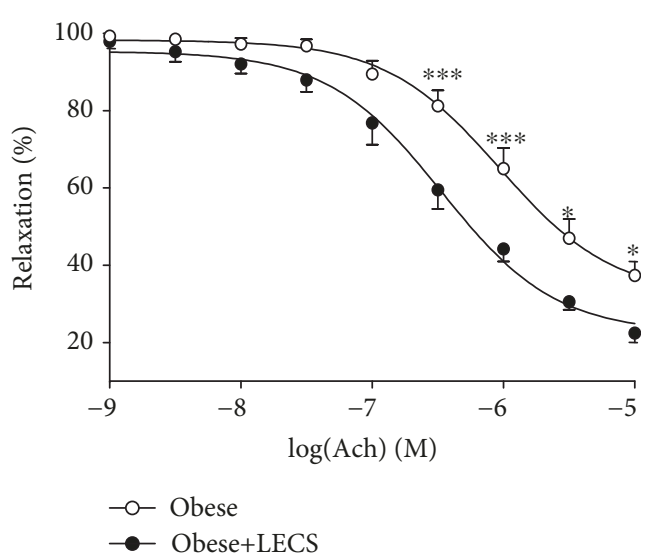

(b)

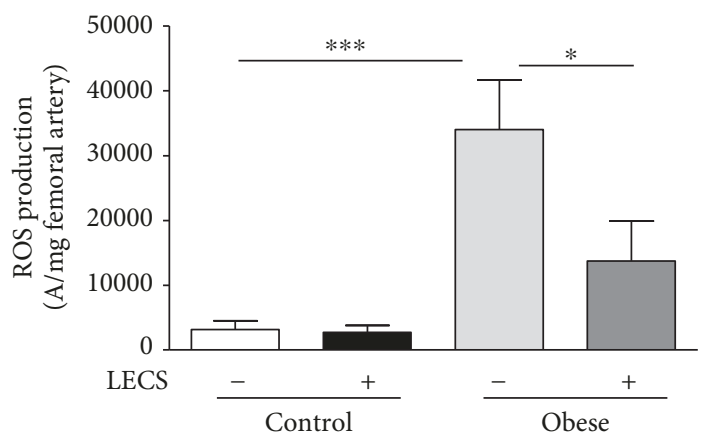

(d)

FIgURE 6: LECS induces vascular endothelial protective activities. Concentration-response curves to Ach in (a) lean and (b) $o b / o b$ mice. (c) NO and (d) ROS productions in the femoral artery. The results are expressed as mean \pm S.E.M. $\left(n=8 /\right.$ group; ${ }^{*} p<0.05$ and $\left.{ }^{* * * *} p<0.001\right)$.

was accompanied by increase of both insulin and AMPK pathways in the liver and skeletal muscle. Additionally, LECS completely prevented the endothelial dysfunction resulting from an increased $\mathrm{NO}^{\circ}$ and decreased ROS production. Thus, LECS not only improves glycemic control and insulin resistance but also improves the endothelial function of $o b / o b$ mice.

Indeed, based on the experimental model used in the present study, the ob/ob mouse develops obesity as early as 1 month of age with progressively increasing food intake, body weight, glycemia, insulin levels, insulin resistance, and pancreatic, hepatic, and endothelial dysfunction through leptin deficiency in the hypothalamus [19].

It is interesting to note that oral administration of LECS, at the dosage used, did not significantly decrease body weight and daily food intake in ob/ob mice. Thus, LECS did not induce toxicity or orexigenic effects under the experimental condition used. These results are in accordance with previous studies with traditional consumption of this plant. In line with these data, young fruits and leaves of Cassia siamea are consumed as vegetables in Thailand and India [20], without obvious orexigenic and toxic actions [11].

The most important finding of the present study was the amelioration of the diabetic-related glucose tolerance and insulin resistance state by the LECS treatment, as shown by the restoration of hyperglycemia and reduction of insulinemia without hypoglycemic or hypoinsulinemic effect in lean mice and the increased insulin sensitivity. Thus, daily feeding of mice for 4 weeks with LECS $(200 \mathrm{mg} / \mathrm{kg}$ ) is adequate to produce a sufficient circulating concentration of compounds to induce metabolic and vascular effects. In our previous study, LECS exhibits an antihyperglycemic effect in nondiabetic rats after induction of hyperglycemia with $2 \mathrm{~g} / \mathrm{kg}$ of glucose feeding within 1-5 h [21]. In addition, oral administration of leaf methanolic extract $(250,500 \mathrm{mg} / \mathrm{kg})$ for 3 weeks decreases high blood glucose levels in streptozotocin diabetic rats [14].

The sequence of events leading to the development of insulin resistance in diabetes is incompletely understood. Because of the central role of the liver and skeletal muscle in the whole-body energy homeostasis, both the liver and the skeletal muscle insulin sensitivity appear to be crucial in the development of this state. In the present study, we found that LECS increased the expression of phosphorylated $\mathrm{IR}_{\beta}$, Akt, and AMPK, which were inhibited in $o b / o b$ mice. Thus, it is likely that LECS activates signaling pathways known to improve insulin sensitivity including insulin receptor substrate-1, phosphatidylinositol-3-kinase, protein kinase B (PKB/Akt), and AMPK phosphorylation. Although we did not find any change in GLUT2 or GLUT4 expressions, activation of these signaling pathways is known to promote translocation of GLUT2 in the liver and GLUT4 in the muscle. Such a mechanism might be implicated in the ability of LECS to prevent the development of an 


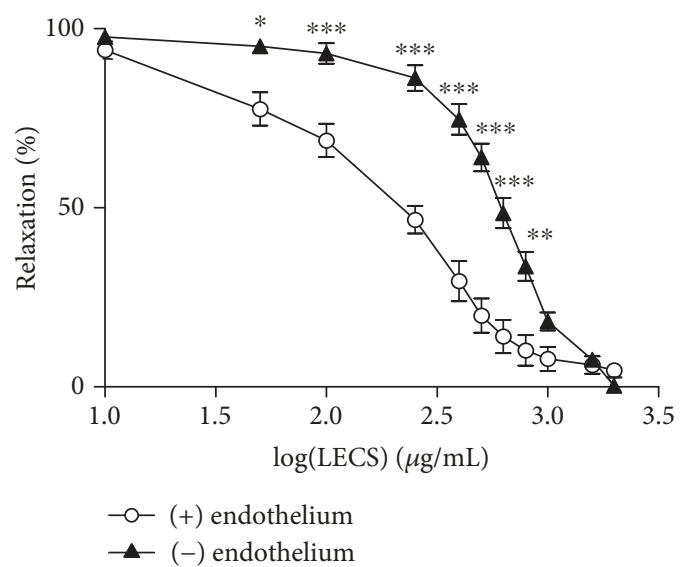

(a)

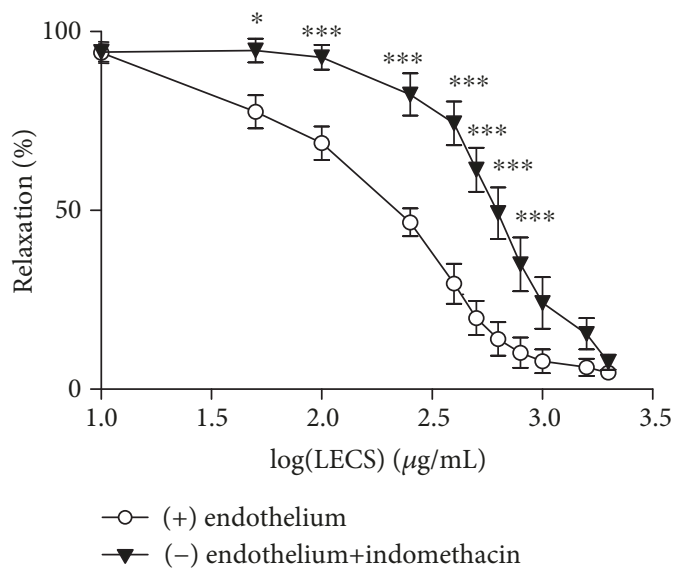

(c)

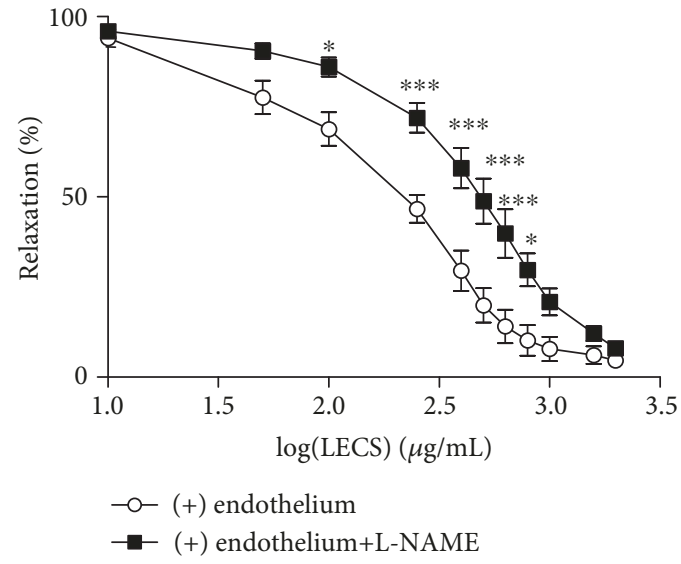

(b)

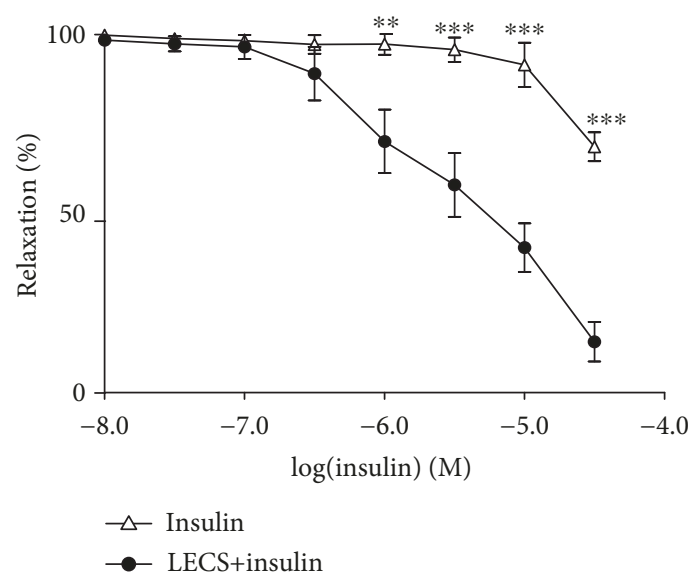

(d)

FIGURE 7: LECS induces endothelium-dependent and endothelium-independent relaxation. Concentration-response curves for LECSinduced relaxation in wild-type aortic rings with and without endothelium (a) and with endothelium in the presence of either L-NAME $\left(10^{-4} \mathrm{M}\right)(\mathrm{b})$ or indomethacin $\left(10^{-5} \mathrm{M}\right)(\mathrm{c})$, and effects of LECS on insulin vasorelaxation action (d). The results are expressed as mean $\pm \mathrm{S}$. E.M. $\left(n=5\right.$ /group; ${ }^{*} p<0.05,{ }^{* *} p<0.01$, and $\left.{ }^{* * *} p<0.001\right)$.

insulin resistant state observed in $o b / o b$ mice in the present study.

Progression of chronic diabetes in $o b / o b$ mice is also associated with the development of hyperlipemia in addition to insulin resistance [22]. Hyperlipemia is characterized by the increase of serum free fatty acid, triglyceride, and total cholesterol [23]. Previously, we reported that organic extracts of Cassia siamea display potential antiobesity compounds via its inhibitory activity on the pancreatic lipase. Such a mechanism may also play a role in the antidiabetic property of LECS although it did not modify plasma lipid levels in the present study.

Chronic mild elevations of hepatic transaminases, such as ALT and AST, are frequently found in type 2 diabetes [24]. The underlying mechanism of diabetes that contributes to liver damage is the combination of increased oxidative stress and an aberrant inflammatory response, which activates the transcription of proapoptotic genes and damages hepatocytes [25]. Interestingly, LECS treatment normalized the levels of AST and ALT in the present study. The high antioxidant potency of Cassia siamea may be responsible at least in part for its hepatoprotective activity [12].

Endothelial dysfunction has been described to be inextricably associated with obesity and insulin resistance [26]. Indeed, insulin receptors are present on endothelial cells, and the disruption of endothelial insulin signaling may affect endothelial function [27]. At physiological concentrations, insulin stimulates both endothelial NO-synthase activity and expression in endothelial cells and promotes endothelium-dependent relaxation [28, 29]. The phosphorylation of eNOS at Ser 1177 can be blunted by hyperglycemia [30] and elevated concentrations of saturated free fatty acid under conditions of vascular insulin resistance. Most importantly, we found that LECS completely restored the endothelial dysfunction in $o b / o b$ mice, probably due to enhanced insulin sensitivity as discussed above. The impaired relaxation to Ach in ob/ob mice was associated with a significant decrease of $\mathrm{NO}^{\circ}$ and an increase of ROS productions in the femoral artery. Interestingly, LECS significantly inhibited the increase of ROS in the femoral artery from $o b / o b$ mice. 
Indeed, various extracts of Cassia siamea have been reported to possess high antioxidant potential [11]. In line with the in vivo effects, LECS promotes endothelium-dependent relaxation via $\mathrm{NO}$-synthase and $\mathrm{COX}$ inhibitor-sensitive mechanisms and potentiates insulin-induced relaxation ex vivo in control mice. Thus, LECS itself can act on the endothelium with special emphasis on endothelial NOsynthase activation and NO release. Together, these data may suggest that an increased antioxidant defense mechanism occurs to reduce oxidative stress in these animals and therefore participates in the restoration of endothelial function and NO bioavailability in conjunction with the direct effect of LECS on the endothelium with respect to NO and COX-vasodilatory metabolites. All these effects concur with the protective effects of LECS on endothelial dysfunction. The latter may also participate in the correction of metabolic features of this experimental model of diabetes with severe obesity.

The identification of the exact mechanism by which LECS reduced insulinemia has not been assessed and represented a limitation of the present study. Nevertheless, we have reviewed previously that LECS contains lupeol, D-pinitol, luteolin, and some dihydronaphtalenone. These compounds might be implicated in the in vivo effect of LECS and, hence, might act on the tissues regulating insulin resistance such as the liver and skeletal muscle and also the endothelium in vivo. Further studies are needed to identify the compounds that support the LECS effects.

\section{Conclusion}

The present study provides scientific basis and evidence for the safe use of Cassia siamea by traditional healers on the preventive/curative purposes for diabetic symptoms. Thus, LECS concomitantly corrected the metabolic and endothelial alterations in an experimental model of diabetes. Improved glucose tolerance, insulin sensitivity, liver function, and endothelial function participate to these beneficial effects of LECS probably via activation of insulin and AMPK pathways. This study supports the hypothesis that Cassia siamea may be therapeutically relevant in reducing metabolic and cardiovascular risks in patients with type 2 diabetes.

\section{Data Availability}

The data used to support the findings of this study are included within the article.

\section{Conflicts of Interest}

The authors declare that they have no competing interests.

\section{Authors' Contributions}

Camille Koffi performed the experiments, acquired and analyzed the data, interpret and discussed the results, and wrote and revised the manuscript. Raffaella Soleti performed the experiments, acquired and analyzed the data, interpret and discussed the results, and wrote and revised the manuscript.
Mathieu Nitiema performed the experiments and acquired the data. Patricia Mallegol performed the experiments and acquired and analyzed data. Gregory Hilairet performed the experiments and acquired the data. Julien Chaigneau performed the experiments and acquired the data. Jerome Boursier performed the experiments and acquired the data. Mamadou Kamagate interpret and discussed the results. Le Lay Soazig provided the mice and revised the manuscript. Henri Maxime Die-Kakou interpret and discussed the results. Ramaroson Andriantsitohaina conceived and designed the experiments, interpret and discussed the results, and wrote and revised the manuscript. All authors read and approved the final manuscript. Camille Koffi and Raffaella Soleti are co-first authors.

\section{Acknowledgments}

We are grateful to Mireille Wertheimer and the staff of "Service Commun d'Animalerie Hospitalo-Universitaire" of Angers for taking care of the animals. This work was supported by the France-Ivory Coast cooperation project AMRUGE-CI (Campus France No. 854039K), by a scholarship from the Ministry of Superior Education and Scientific Research of Ivory Coast (Decision No. 459/MERS/DB/SDBHCI-12/10/2015), by the Université d'Angers as an international mobility, and by the INSERM funding.

\section{References}

[1] J. E. Shaw, R. A. Sicree, and P. Z. Zimmet, "Global estimates of the prevalence of diabetes for 2010 and 2030," Diabetes Research and Clinical Practice, vol. 87, no. 1, pp. 4-14, 2010.

[2] T. Yuan, T. Yang, H. Chen et al., "New insights into oxidative stress and inflammation during diabetes mellitus-accelerated atherosclerosis," Redox Biology, vol. 20, pp. 247-260, 2019.

[3] A. G. Zaman, Q. Aleem, and R. Ahmed, "Reducing cardiovascular risk in patients with type 2 diabetes mellitus," Medicine, vol. 47, no. 2, pp. 72-76, 2019.

[4] A. Sofowora, E. Ogunbodede, and A. Onayade, "The role and place of medicinal plants in the strategies for disease prevention," African Journal of Traditional, Complementary, and Alternative Medicines, vol. 10, no. 5, 2013.

[5] G. Abbas, A. Al Harrasi, H. Hussain, A. Hamaed, and C. T. Supuran, "The management of diabetes mellitus-imperative role of natural products against dipeptidyl peptidase- $4, \alpha$-glucosidase and sodium-dependent glucose co-transporter 2 (SGLT2)," Bioorganic Chemistry, vol. 86, pp. 305-315, 2019.

[6] S. Gothai, P. Ganesan, S. Y. Park, S. Fakurazi, D. K. Choi, and P. Arulselvan, "Natural phyto-bioactive compounds for the treatment of type 2 diabetes: inflammation as a target," Nutrients, vol. 8, no. 8, p. 461, 2016.

[7] C. J. Bailey and C. Day, "Metformin: its botanical background," Practical Diabetes International, vol. 21, no. 3, pp. 115-117, 2004.

[8] M. Puri, H. Masum, J. Heys, and P. A. Singer, "Harnessing biodiversity: the Malagasy Institute of Applied Research (IMRA)," BMC International Health and Human Rights, vol. 10, Supplement 1, p. S9, 2010.

[9] D. K. Patel, R. Kumar, D. Laloo, and S. Hemalatha, "Diabetes mellitus: an overview on its pharmacological aspects and 
reported medicinal plants having antidiabetic activity," Asian Pacific Journal of Tropical Biomedicine, vol. 2, no. 5, pp. 411420, 2012.

[10] M. Eddouks, A. Bidi, B. el Bouhali, L. Hajji, and N. A. Zeggwagh, "Antidiabetic plants improving insulin sensitivity," The Journal of Pharmacy and Pharmacology, vol. 66, no. 9, pp. 1197-1214, 2014.

[11] M. Kamagaté, C. Koffi, N. M. Kouamé, A. Akoubet, N. A. R. Yao, and H. M. Die-Kakou, "Ethnobotany, phytochemistry, pharmacology and toxicology profiles of Cassia siamea Lam," The Journal of Phytopharmacology, vol. 3, pp. 57-76, 2014.

[12] G. Kaur, M. S. Alam, Z. Jabbar, K. Javed, and M. Athar, "Evaluation of antioxidant activity of Cassia siamea flowers," Journal of Ethnopharmacology, vol. 108, no. 3, pp. 340-348, 2006.

[13] C. Koffi, M. Kamagate, E. Koffi et al., "Aqueous extract of Cassia siamea Lam leaves exhibited antihyperglycemic effect and improved kidney function in diabetic Wistar rats," International Journal of Pharmacological Research, vol. 6, pp. 336-342, 2016.

[14] S. Kumar, V. Kumar, and O. M. Prakash, "Antidiabetic and anti-lipemic effects of Cassia siamea leaves extract in streptozotocin induced diabetic rats," Asian Pacific Journal of Tropical Medicine, vol. 3, no. 11, pp. 871-873, 2010.

[15] T. Matsumoto, T. Kobayashi, K. Ishida et al., "Vasodilator effect of cassiarin A, a novel antiplasmodial alkaloid from Cassia siamea, in rat isolated mesenteric artery," Biological \& Pharmaceutical Bulletin, vol. 33, no. 5, pp. 844-848, 2010.

[16] D. Kumar, A. Karmase, S. Jagtap, R. Shekhar, and K. K. Bhutani, "Pancreatic lipase inhibitory activity of Cassiamin A, a Bianthraquinone from Cassia siamea," Natural Product Communications, vol. 8, no. 2, p. 1934578X1300800, 2013.

[17] D. Leonetti, R. Soleti, N. Clere et al., "Estrogen receptor $\alpha$ participates to the beneficial effect of red wine polyphenols in a mouse model of obesity-related disorders," Frontiers in Pharmacology, vol. 7, 2017.

[18] A. Lavaud, R. Soleti, A.-E. Hay, P. Richomme, D. Guilet, and R. Andriantsitohaina, "Paradoxical effects of polyphenolic compounds from Clusiaceae on angiogenesis," Biochemical Pharmacology, vol. 83, no. 4, pp. 514-523, 2012.

[19] M. Thon, T. Hosoi, and K. Ozawa, "Possible integrative actions of leptin and insulin signaling in the hypothalamus targeting energy homeostasis," Frontiers in Endocrinology, vol. 7, 2016.

[20] Y. R. A. Smith, "Determination of chemical composition of Senna-siamea (cassia leaves)," Pakistan Journal of Nutrition, vol. 8, no. 2, pp. 119-121, 2009.

[21] K. J. Ravi, R. B. Ganga, N. M. Lakshmi, and R. T. Mallikarjun, "Evaluation of antidiabetic activity of Cassia siamea leaves in alloxan induced diabetic rats," International Journal of Phytopharmacology, vol. 4, pp. 237-240, 2013.

[22] A. J. Kennedy, K. L. J. Ellacott, V. L. King, and A. H. Hasty, "Mouse models of the metabolic syndrome," Disease Models \& Mechanisms, vol. 3, no. 3-4, pp. 156-166, 2010.

[23] B. Klop, J. W. F. Elte, and M. C. Cabezas, "Dyslipidemia in obesity: mechanisms and potential targets," Nutrients, vol. 5, no. 4, pp. 1218-1240, 2013.

[24] E. H. Harris, "Elevated liver function tests in type 2 diabetes," Clinical Diabetes, vol. 23, no. 3, pp. 115-119, 2005.

[25] J. Mohamed, A. H. Nazratun Nafizah, A. H. Zariyantey, and S. B. Budin, "Mechanisms of diabetes-induced liver damage: the role of oxidative stress and inflammation," Sultan Qaboos University Medical Journal, vol. 16, no. 2, pp. e132-e141, 2016.
[26] D. Prieto, C. Contreras, and A. Sánchez, "Endothelial dysfunction, obesity and insulin resistance," Current Vascular Pharmacology, vol. 12, no. 3, pp. 412-426, 2014.

[27] E. R. Duncan, P. A. Crossey, S. Walker et al., "Effect of endothelium-specific insulin resistance on endothelial function in vivo," Diabetes, vol. 57, no. 12, pp. 3307-3314, 2008.

[28] C. Contreras, A. Sánchez, A. García-Sacristán, M. C. Martínez, R. Andriantsitohaina, and D. Prieto, "Preserved insulin vasorelaxation and up-regulation of the Akt/eNOS pathway in coronary arteries from insulin resistant obese Zucker rats," Atherosclerosis, vol. 217, no. 2, pp. 331-339, 2011.

[29] T. Kobayashi and K. Kamata, "Effect of chronic insulin treatment on NO production and endothelium-dependent relaxation in aortae from established STZ-induced diabetic rats," Atherosclerosis, vol. 155, no. 2, pp. 313-320, 2001.

[30] X. L. Du, D. Edelstein, S. Dimmeler, Q. Ju, C. Sui, and M. Brownlee, "Hyperglycemia inhibits endothelial nitric oxide synthase activity by posttranslational modification at the Akt site," The Journal of Clinical Investigation, vol. 108, no. 9, pp. 1341-1348, 2001. 


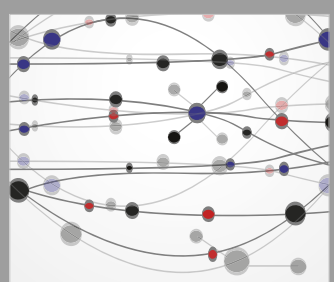

The Scientific World Journal
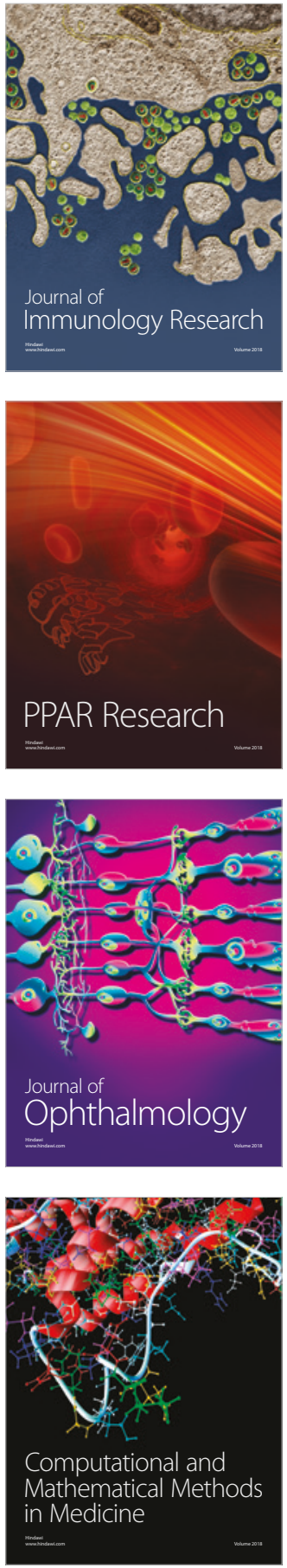

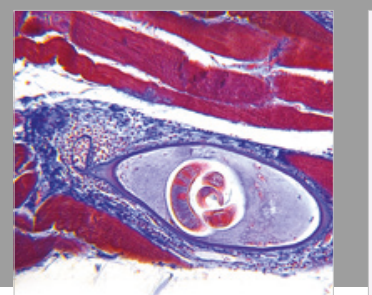

Gastroenterology Research and Practice

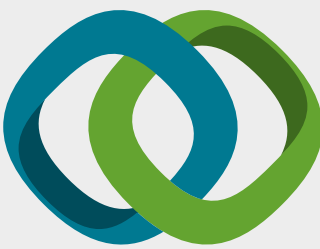

\section{Hindawi}

Submit your manuscripts at

www.hindawi.com
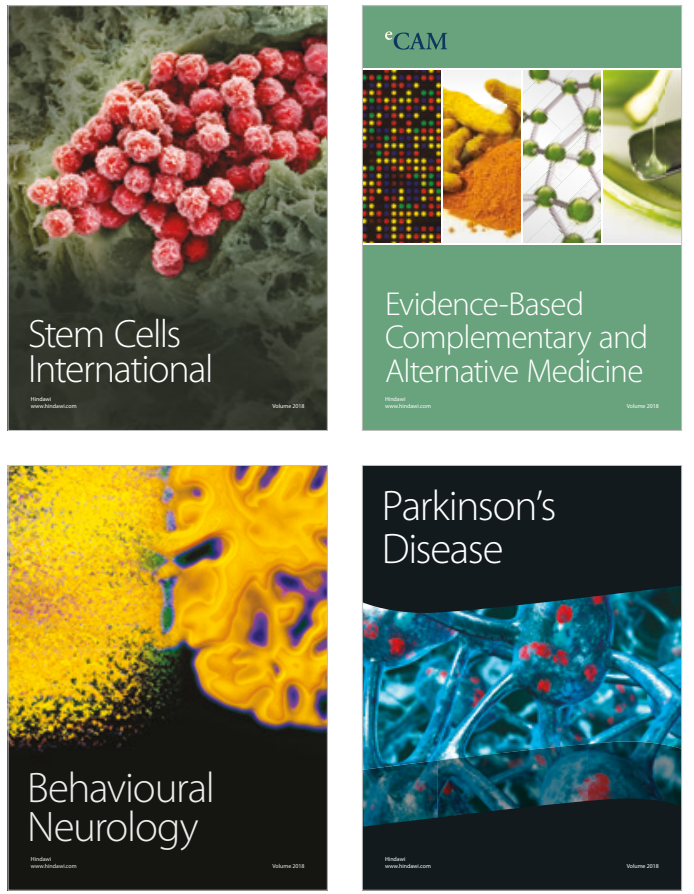

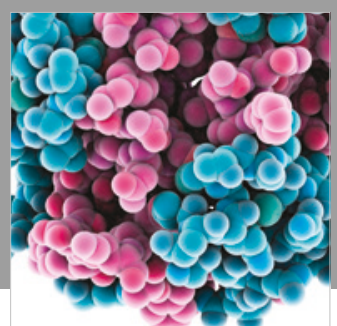

ournal of

Diabetes Research

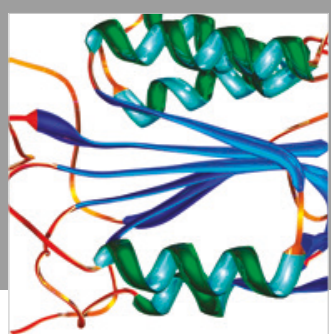

Disease Markers
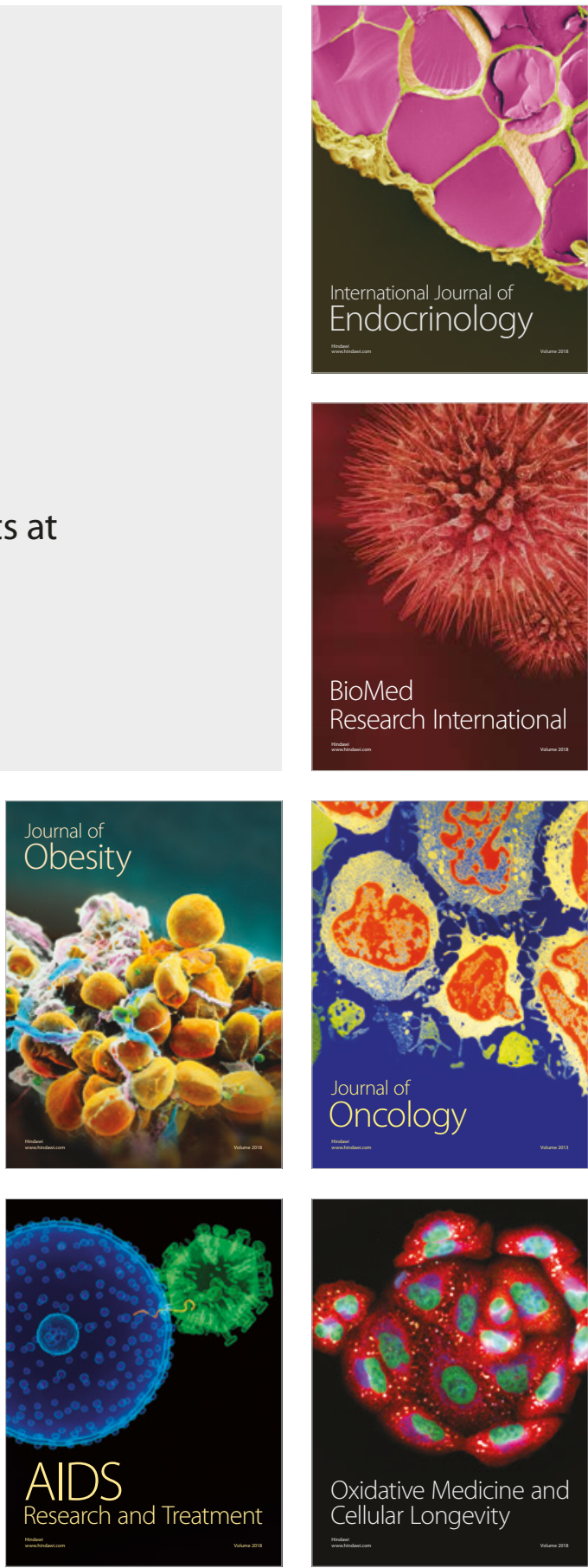